\section{PITCHER PLANTS}

$D^{17}$ FFERENCE of opinion has been expressed as to the nature and use of the lquid found in the socalled pitchers of various plants, such as Nepenthes, Raffesi: and certain Orchidaceæ. The popular idea that these curious recepracles collect pure water for the refreshment of the thirity in arid places, would seem to be set at rest, by a consideration of the fact that these plants grow in moist and marshy places. There would seem, moreover, to be some improbability that plants should secrete pure water.

In this country, where these plants are grown under exceptional conditions, there is some difficulty in settling these questions experimentally. In such cases, extraneous water often finds its way into the pitchers, so that several ounces may frequently be gathered from a single receptacle of Nepenthes, the greater part of which is accidental.

In August last I had an opportunity of collecting the liquid from two flowers of Coryanthes, one of the Orchidacer, whicl had just opened, in one of the well-known stove-houses of Mr. Wilson Saunders.

Though the quantity collected was small, amounting only to about thice cubic centimetres, or I'I 8 cubic inches, an examination showed the following properties:-

Clear and some: sessed of a high refractive power, and a specific gravity of . I'062.

Odour pleasant but faint, becoming more marked by a gentle heat. Neutral to test papers. Becoming milky, by concentration on the water-bath, it finally yielded a transparent gum, insoluble in alcohol.

Oxalates produced no precipitate of lime, but basic lead acetate gave a curdy reaction. Concentrated hot sulphuric acid blackened the liquid.

Although the taste was not acrid, the mawkish flavour would render it quite unpotable.

This examination therefore proved the liquid to be somt:thing else than pure water.

Ioo parts of liquid contained :-

Water and volatile oils . . $98 \cdot 5$

Non-volatile residue. . . I*49

$100 \cdot 00$

G. B. BUCKTON

\section{SPECTROSCOPIC OBSERVATIONS OF THE $S U N$}

PROF. C. A. YOUNG has obligingly sent me an account of his recent work, which is very rich in promise, as he telis me that he has now the dispersive power of 13 prisms of heavy flint, each with an angle of $55^{\circ}$. It is now some time aon since I announced to the Koyal Society that over sonts prominences, built up of different va oura, ware somctimes obscrvable by means of their lines, brigrit and thin, overlying the thick absorption lines in the spot spectra. This observation is, I hold, a clear prouf of the truth of the theory put forward by Dr. Frankland and myself, namely, that changes in spectra, notably the thickening of the lines, are due to pressure, and not to temperature; for according to the theory of exchanges, the bright prominence must be hotter than the absorbing vapour which underlies it, and still the lines are thinner.

Dr. Young has now observed these phenomena with exactly the sime result. He writes to Professor Morton:-

"I write to inform you that last Thursday, Sept. 22, about If A.M. Hanover mean time, I was so fortunate as to see the sotium lines $D_{1}$ and $D_{2}$, reversed in the spectrum of the umbra of a large spot near the eastern limb of the sun. At the same time the $\mathrm{C}$ and $\mathrm{F}$ lines were also reversed, but with the great dispersive power of my new spectroscope I see this so often in the solar spots, that it has ceased to be remarkable.

"The figure gives the appearance of the sodium lines. In the umbra of the spot the $D_{3}$ line was not visible, but in the penumbra was plainly seen, as a dark shade, represinted in the figure.

"I am not aware that this reversal of the sodium lines in a spot spectrum has ever been observed before; its reversal in the spectra of prominences is not very unusual. A small prominence on the western limb of the sun, which was visible the same forenoon, presented all the following bright lines, viz. : $\mathrm{C}, \mathrm{D}_{1}, \mathrm{D}_{2}, \mathrm{D}_{3}, 1474, b_{1}, b_{2} . b_{4}, 1989.5$, $200 I^{\prime} 5,203 \mathrm{I}^{\prime}, \mathrm{F}, 25^{\circ} \mathrm{I}^{\circ} 5,2796$; , and $h$; 15 in all.

"In the spot spectrum the magnesium lines $b_{1}, b_{2}$, and $b_{4}$ were not reversed, but while the shade which accompanies the lines was perceptibly widened, the central black line itself was thinned and lightened."

Further, Prof. Young has succeeded in obtaining photographs of protuberances on the sun's limb, of which he has been good enough to forward me a specimen. They were obtained by attaching a small camera to the eye-piece of the telescope and opening the slit somewhat widely, using the hydrogen line near $\mathrm{G}$. He adds:- "As a picture, the little thing amounts to nothing, because the unsteadiness of the air and the maladjustment of the polar axis of the equatorial caused the image to shift its place slightly during the long exposure of three-and-a-half minutes which was required, thus destroying all the details. Still, the double-headed form of the prominence is evident, and the possibility of taking such photographs is established."

In a letter to myself Prof. Young adds:- "I should not have published so imperfect a success were it not that my engagement as a member of Prof. Winlock's eclipse party prevents me from following up the matter at present. The experiments were tried on the $28 \mathrm{th}$, and on the 3 oth the eqtatorial was taken down to be packed up and sent to the rendezvous, at Alvan Clark's factory, where all the instruments are collectea and put in order previous to sailing." J. NORMAN LOCKYER

\section{NOTES}

Since our last issue the Joint Committee of the Royal and Royal Astronomical Societies and the Council of the British Association have met to consider the question of the Eclipse Expedition, and in consequence of these meetings Mr. Gladstone has been asked to receive a joint deputation to urge upon the Government the importance of the proposed expedition. The Joint Committee have appointed the Presidents of the Royal and Royal Astronomical Societies, the Astronomer Royal, and Mr. Lockyer to plead its cause; while the Council of the British Association will be represented by the President and officers of the Association, Sir John Lubbock, M.P., and Dr. Lyon Playfair, M.P. I'p to the time of our going to press, however, no time had been fixed for the deputation to wait upon the Prime Minister.

THE medals in the gift of the Royal Society have this year been awarded as follows:-The Copley medal to Dr. Joule; the Rumford medal to $M$. Descloiseaux; and the Royal medals to Prof. W. H. Miller and Mr. W. Davidson.

Prof. Simon Nrwcomb has arrived in this country from the United States Naval Observatory. His mission among us is to examine and report on the great Newall telescope. $\mathrm{He}$ will then proceed to Gibraltar to observe the approaching eclipse.

AII members of the British Association will be concerned to learn that Dr. Hirst feels called upon by the pressure of his new duties to resign the General Secretaryship of the Association, an honorary post which he has long filled with the greatest advantage to Science. 